\title{
Fetal Development of the Bovine Uterus: A Light Microscopy and Immunohistochemical Study
}

\author{
Rebecca A.-M. Kenngott Fred Sinowatz \\ Department of Veterinary Sciences, Institute for Anatomy, Histology, and Embryology, Ludwig Maximilian University, \\ Munich, Germany
}

\author{
Key Words \\ Bovine uterus · Differentiation - Fetus . \\ Immunohistochemical staining
}

\begin{abstract}
Important steps during the prenatal development of the bovine uterus are described using conventional hematoxylineosin staining of fetuses from different developmental stages [crown-rump length (CRL) $9.2-94.0 \mathrm{~cm}$ ]. Additionally, a number of intermediate filaments (keratin 7, 8, 14, 18, 19; and vimentin), the basement membrane protein laminin, smooth-muscle marker (SMA), and S100 were studied to further characterize certain differentiation processes. During early development, the uterine epithelium is simple or (pseudo)stratified with bud-like protrusions. Developing caruncles can be observed in the corpus uteri at a CRL of 15.8 $\mathrm{cm}$ onwards, showing a simple, keratin-positive epithelium. In contrast, the intercaruncular areas are characterized by a (pseudo)stratified epithelium, which also shows positive staining in a different manner for the investigated keratins. A differentiation of smooth muscle cell layers can be observed from a CRL of $24.4 \mathrm{~cm}$ onwards. Intense SMA-positive cells/fibers, arranged perpendicularly to the developing circular SMA-positive muscle cell layer, can be found preferen-
\end{abstract}

tially located in the developing caruncles. Lymphocytes occur in the uterine epithelium and stroma in the corpora and cornua of fetuses with a CLR of $15.8 \mathrm{~cm}$ and higher.

(c) 2016 S. Karger AG, Basel

The uterus of many mammalian species has been described using established histological techniques during different stages of the reproductive life [King et al., 1979; Boos, 2000; Taylor et al., 2000; Gray et al., 2001; Carpenter et al., 2003; Gray et al., 2003; Hayashi et al., 2005], but only few studies have concentrated on its prenatal development. The uterus is formed by the fusion of caudal parts of the Müllerian ducts [Baumgartner, 1910; Rüsse and Sinowatz, 1998; Spencer et al., 2012; König and Liebich, 2014]. Paranko et al. [1985] and Paranko and Virtanen [1986] described the differentiation process of the early genital ducts with different tissue markers in rats. Konishi et al. [1984] studied the differentiation of the smooth muscle layer in the human prenatal uterus using ultrastructural techniques. Differentiation of the bovine endometrium in fetuses ranging from days 151 to 282 has been described by Atkinson et al. [1984]. Wiley et al. [1987] studied the histogenesis of the uterus in fetal and neonatal lambs with special focus on the caruncular (nod-

\section{KARGER 125}

(c) 2016 S. Karger AG, Base

$1661-5425 / 16 / 0096-0316 \$ 39.50 / 0$

E-Mail karger@karger.com

www.karger.com/sxd
Rebecca A.-M. Kenngott

Department of Veterinary Sciences

Institute for Anatomy, Histology, and Embryology, Ludwig Maximilian University

Veterinärstrasse 13, DE-80539 Munich (Germany)

E-Mail r.kenngott@anat.vetmed.uni-muenchen.de 
Table 1. Overview of the used antibodies

\begin{tabular}{|c|c|c|c|c|}
\hline Keratin 7 & monoclonal, mouse, $1: 100,20 \mathrm{~h}$ at $4^{\circ} \mathrm{C}$ & Progen & Rabbit anti-mouse, 1:300 & 61025 \\
\hline Keratin 8 & monoclonal, mouse, $1: 500,20 \mathrm{~h}$ at $4^{\circ} \mathrm{C}$ & Novus Biologicals & Rabbit anti-mouse, 1:300 & NB500-349 \\
\hline Keratin 18 & polyclonal, guinea pig, $1: 200,20 \mathrm{~h}$ at $4^{\circ} \mathrm{C}$ & Progen & Goat anti-guinea pig, 1:300 & GP-CK18 \\
\hline Keratin 19 & polyclonal, guinea pig, $1: 200,20 \mathrm{~h}$ at $4^{\circ} \mathrm{C}$ & Progen & Goat anti-guinea pig, 1:300 & GP-Ck19 \\
\hline SMA & monoclonal, mouse, $1: 40,1 \mathrm{~h}$ at RT & Dako & Rabbit anti-mouse, 1:300 & M0851 \\
\hline S100 & polyclonal, rabbit, 1:400, $30 \mathrm{~min}$ at $\mathrm{RT}$ & Dako & Pig anti-rabbit, 1:300 & Z0311 \\
\hline Laminin & polyclonal, rabbit, $1: 500,20 \mathrm{~h}$ at $4^{\circ} \mathrm{C}$ & Serotec & Pig anti-rabbit, 1:300 & AHP420T \\
\hline
\end{tabular}

The secondary antibodies were all incubated for $30 \mathrm{~min}$ at room temperature (RT).

ular) and internodular endometrial development and differentiation. Spencer et al. [2012] described the hormonal, cellular, and molecular processes and also pathological pathways during uterus development.

In the present study we give a short overview of the prenatal development of the bovine uterus with a special focus on differences between caruncular and intercaruncular areas, the expression patterns of the intermediate filaments, and the development process of the caruncles.

\section{Material and Methods}

\section{Sampling and Preparation of Prenatal Uteri}

Collection, cutting, fixation, and preparation of prenatal uteri has been performed similar to previous studies [Kenngott and Sinowatz, 2007, 2008], using modifications of histological techniques described in Mulisch and Welsch [2010].

After saving prenatal bovine uteri of various development stages of 20 bovines (crown-rump length (CRL) between $9.2 \mathrm{~cm}$ and $94.4 \mathrm{~cm}$ ), the respective corpora and cornua uteri were fixed in Bouin's solution [Mulisch and Welsch, 2010] as well as in 3.7\% phosphate-buffered formalin [Mulisch and Welsch, 2010] for 12$24 \mathrm{~h}$ (with exception of the uterus with a CRL of $9.2 \mathrm{~cm}$ which was processed in toto). Dehydration (graded series of alcohols) and embedding in paraffin was accomplished according to a standard tried and tested workflow (Institute of Anatomy, Histology, and Embryology). Serial sections $(5 \mu \mathrm{m})$ were gathered from each tissue sample by means of a Leitz microtome (Typ1516; Leitz, Germany) and subsequently stained with hematoxylin-eosin according to Mulisch and Welsch [2010].

\section{Immunohistochemical Staining}

Immunohistochemistry was carried out analog to the work sequence, congruent with the techniques of Mulisch and Welsch [2010] and adapted to the use of the antibodies in our study. This protocol is previously described at length in our investigation on

Fetal Development of the Bovine Uterus the bovine genital tract [Kenngott and Sinowatz, 2007, 2008; Kenngott et al., 2013]. In brief, 5- $\mu$ m serial sections, affixed on APES (aminopropyltriethoxysilane)-coated slides (SupraFrost Ultra Plus, Menzel-Gläser), were dried overnight at $37^{\circ} \mathrm{C}$ in a dry box. Subsequently, the wax was removed by xylene, and the slides were then pulled through in a series of alcohols, falling in concentration, and at last dipped into distilled water, carefully soaking them with each step. Proteinase XXIV (0.1\%; Sigma, P8038) was utilized, predigesting for $15 \mathrm{~min}$, followed by thoroughly rinsing in PBS buffer ( $\mathrm{pH}$ 7.4). The slides were immersed in $0.1 \% \mathrm{H}_{2} \mathrm{O}_{2}$ at room temperature for $10 \mathrm{~min}$ to rule out the possibility of endogenous peroxidase and to cut down non-specific antibody binding. Dako Protein-Block-Serum-Free was applied for $20 \mathrm{~min}$. After using $\mathrm{ABC}$ technique [Noll and Schaub-Kuhnen, 2000] overnight in humid chambers at $4{ }^{\circ} \mathrm{C}$ and applying the secondary antibody, the slides were again thoroughly soaked in PBS $(3 \times 5 \mathrm{~min})$ followed by visualization through DAB (diaminobenzidine) for 5-10 min. This reaction was halted by a careful rinse with distilled water to finally being weakly counter-stained with hematoxylin (30 s). The polyclonal and monoclonal antibodies used as primary antibodies are listed in table 1.

Negative controls were carried out substituting the specific primary antibody with diluents (Dako). Tissues with established specific immunoreactivity for the corresponding antibodies applied in this study were chosen as positive controls.

\section{Results}

The general nomenclature for the microscopic-anatomical classification of the uterus organization is used according to the description of Liebich [2009].

\section{Short Summary of General Observations Occurring Frequently in Different Prenatal Uterus Stages}

Transverse sections of the uteri from different developmental stages show mostly a round to oval lumen in the 
cornua and corpora. The lumen of the corpus is always larger than the more roundish lumen of the cornua. The histology of the endometrium, myometrium, and perimetrium in the corpus and cornua are identical, but the differentiation process seems to be a little faster in the corpus than in the cornua. In general, epithelium cells with a lighter cytoplasm can be observed between the resting epithelial cells in all investigated stages. From a CRL of $31.0 \mathrm{~cm}$ onwards, prominent cells/fibers can be observed in the caruncles, which are arranged perpendicularly to the longitudinal axis of the uterus, and they are lacking in the intercaruncular areas. Additionally, big vessels, perpendicular to the circular muscular layer, are seen within the caruncles. Scattered polygonal cells can be detected between the smooth muscle cells of the developing tunica muscularis. Tubular-like epithelium invaginations into the underlining stromal tissue are found in the intercaruncular areas of the corpus uteri of fetuses with a CRL of $94.0 \mathrm{~cm}$.

\section{Observations in Different Developing Stages in}

\section{Hematoxylin-Eosin-Stained Sections}

The early uterus epithelium of fetuses with a CRL of $9.2-11.4 \mathrm{~cm}$ is (pseudo)stratified with polygonal strongly stained nuclei, containing 2-3 nucleoli (fig. 1A, B). The apical cell membrane of the epithelial cells is often more distinctly stained. Sometimes big round cells with strongly stained roundish nuclei can be found in the basal or apical area of the epithelium. The mesenchymal cells are undifferentiated and loosely arranged in a radial manner under the epithelium. These cells are polygonal with large nuclei (and 1-2 distinct nuclei). Intercellular spaces with little extracellular matrix can be observed between the mesenchymal cells. No definite zonal differentiation of the surrounding mesenchymal tissue can be precisely distinguished in these stages, and no morphological differences can be seen between the corpus and the cornua.

The epithelium of the uterine corpus of fetuses with a CRL of $15.8 \mathrm{~cm}$ is similar to that of previous stages; however, the high prismatic to (pseudo)stratified epithelium at some location protrudes 'bud-like' into the lumen. Now a subdivision into different zones can be detected (fig. 1C). The stroma of the endometrium underneath the epithelium appears more densely organized and can be clearly distinguished from the resting, more loosely arranged, endometrial stroma cells (first area $=$ endometrium). In contrast, the cells of the second area (later myometrium) are already elongated and show a more longitudinal arrangement compared to the remaining
Fig. 1. Overview of important steps during the fetal development of the bovine uterus. A, B Section through the corpus and cornua uteri of a fetus with a CRL of 11.4 and $15.8 \mathrm{~cm}$. Both segments are lined with a columnar, (pseudo)stratified epithelium. C Detail of the wall of the cornua uteri from a fetus with a CRL of $15.8 \mathrm{~cm}$. The epithelium is highly prismatic, and the apical and basal cytoplasm is weakly stained. The nuclei are arranged mainly in the central cytoplasm of epithelium cells. A faint differentiation into 3 zones can be observed in the mesenchymal wall. D Overview of the wall of the cornua uteri from a fetus with a CRL of $24.4 \mathrm{~cm}$. Note the epithelium folding buds, which protrude into the lumen and the densely packed stroma cells directly under the basal lamina. E Wall detail of the cornua uteri from a fetus with a CRL of $31.0 \mathrm{~cm}$. Three zones can be now distinguished in the corpus uteri wall, and caruncles can also be observed. $\mathbf{F}$ Detail of the the cornua uteri wall from a fetus with a CRL of $31.0 \mathrm{~cm}$. The differentiating smooth muscle cells are spindle-shaped, elongated, and surround the lumen in a radial manner. G Section through the cornua uteri of a fetus with a CRL of $31.0 \mathrm{~cm}$. Prominent caruncles protrude into the lumen of the corpus. $\mathbf{H}$ Detail of the corpus epithelium from a fetus with a CRL of $31.0 \mathrm{~cm}$. The epithelium is more regularly arranged and columnar-shaped. Note the densely sitting stroma cells close to the basal lamina. I Detail of the corpus epithelium from a fetus with a CRL of $44.8 \mathrm{~cm}$. The epithelium in the intercaruncular regions is (pseudo)stratified with no regular arrangement. J Detail of the caruncles epithelium of the corpus from a fetus with a CRL of $44.8 \mathrm{~cm}$. The epithelium of the caruncles apex is more reduced in height with dark stained round nuclei. $\mathbf{K}$, $\mathbf{L}$ Detail of the corpus uteri wall from a fetus with a CRL of $44.8 \mathrm{~cm}$. Different areas can be distinguished in the wall of the uterus. $\mathbf{M}$ Section through the cornua uteri lumen from a fetus with a CRL of $57.6 \mathrm{~cm}$. Note the big caruncle in contrast to the smaller developing caruncles on the other luminal side. $\mathbf{N}$ Section through the cornua uteri lumen from a fetus with a CRL of $66.0 \mathrm{~cm}$. Note the regularly arranged highly prismatic epithelium of the caruncles in contrast to the higher (pseudo)stratified epithelium of early caruncles constructions. O Section through the corpus uteri lumen from a fetus with a CRL of $66.0 \mathrm{~cm}$. Note the multiple well-developed caruncles, which are arranged in close contact to each other. $\mathbf{P}$ Detail of the cornua uteri wall from a fetus with a CRL of $72.5 \mathrm{~cm}$. Note the well-developed and more expanded tunica muscularis. The caruncle stroma under the epithelium is more compact in contrast to the remaining loosely arranged caruncle stroma cells. $\mathbf{Q}$ Section through the intercaruncular regions of the cornua uteri from a fetus with a CRL of 72.5 $\mathrm{cm}$. There are always newly formed epithelial folding buds in the intercaruncular regions. $\mathbf{R}$ Detail of a caruncle from the cornua uteri of a fetus with a CRL of $90.0 \mathrm{~cm}$. Note the numerous small vessels in the caruncle stroma. S, T Section through the cornua uteri of a fetus with a CRL of $94.0 \mathrm{~cm}$. The tunica muscularis is broad with well-differentiated smooth muscle cells. Different vessels and nerve cells can be seen. In the tunica a band of further smooth muscle cells can be observed adjacent to the tunica muscularis. Note the well-developed vessels in the carunclar stroma cells.

(For figure see next page.) 

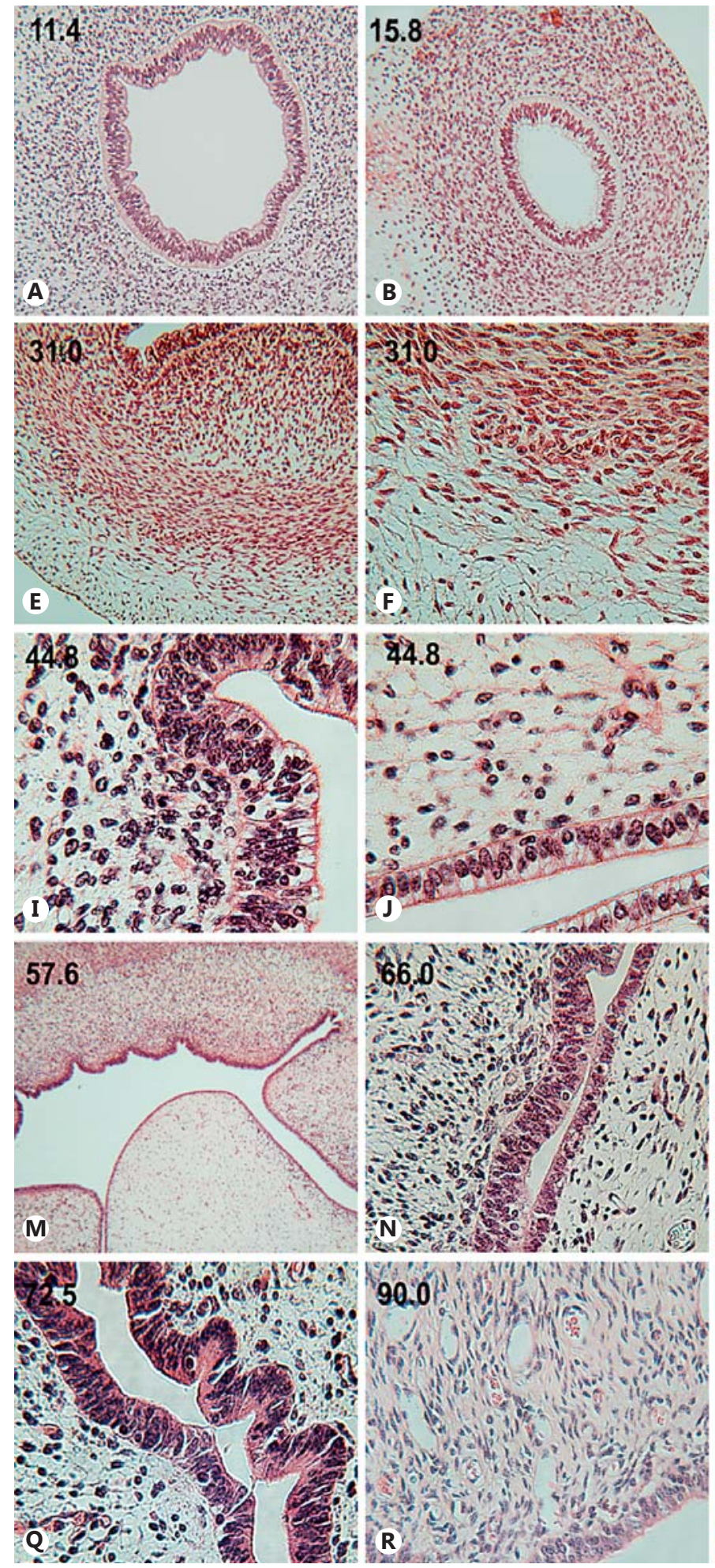

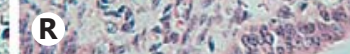
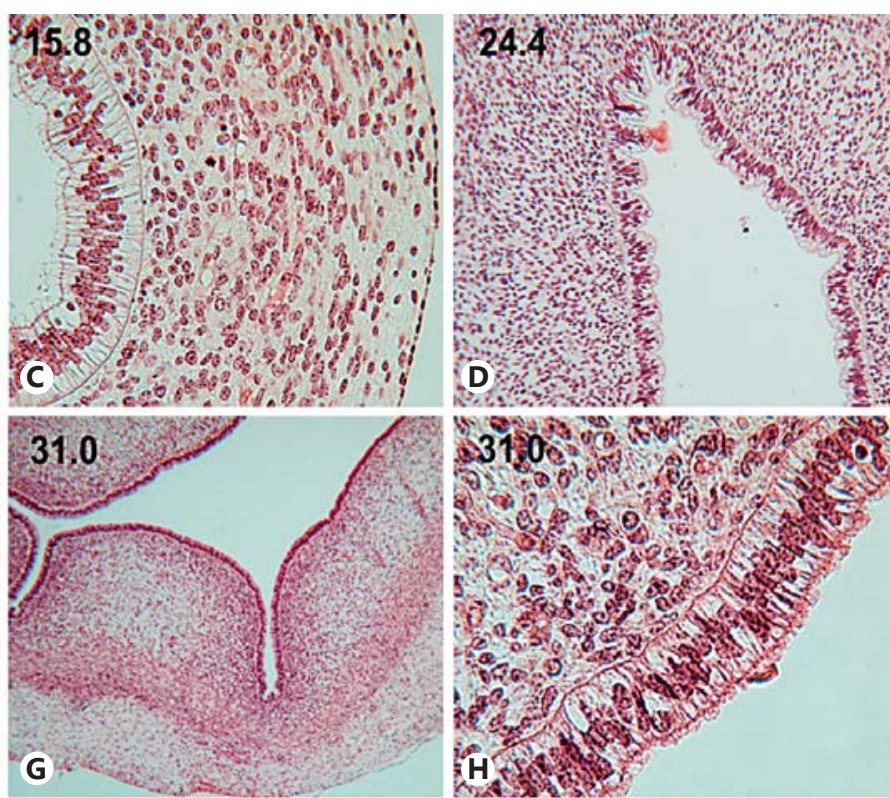

\section{8}

K
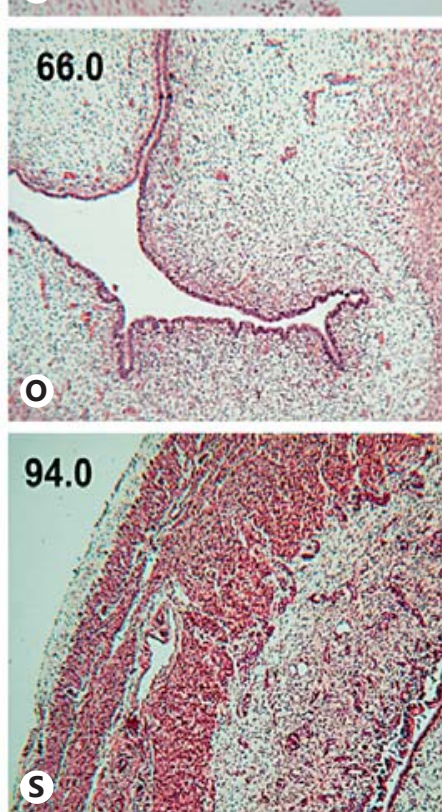

3100 . 2. $20.018 \%$.

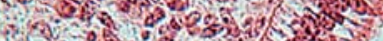
1.29: 0206

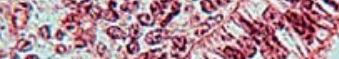
\% 15 sones H. IN
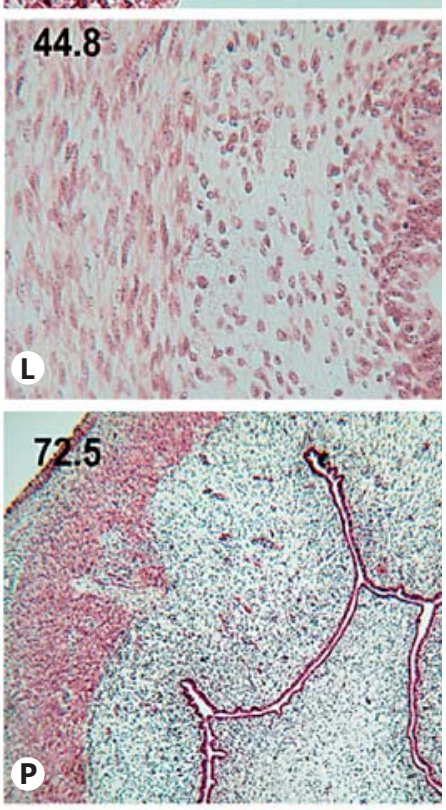

s

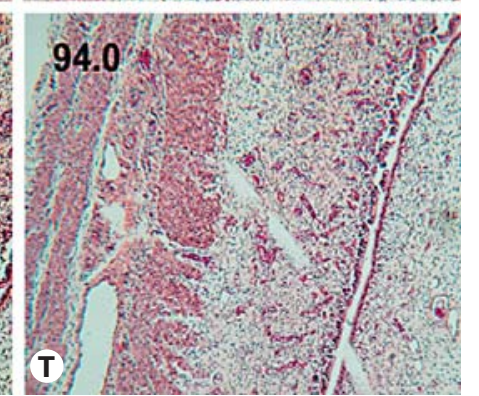


stroma cells. The polygonal cells of the third area (later perimetrium) are loosely ordered with polygonal cells and big intercellular spaces. Small and big vessels are dispersed between the cells, but the bigger vessels are mostly located in the third area. Generally, a nearly identical morphological organization can be recognized in the cornua, but the 'budding process' of the epithelium is less pronounced.

In the corpora as well as in the cornua of fetuses with CRLs of $24.4 \mathrm{~cm}$ (fig. 1D) to $29.8 \mathrm{~cm}$ the epithelium buds increase strongly in number as well as in size. The epithelium itself remains highly prismatic to (pseudo)stratified but appears to be more regularly arranged. The small and polygonal nuclei are located mostly in the central areas of the epithelial cells. Some epithelium buds are now supported by stroma cells, which have increased in size compared to the remaining epithelium buds. In these areas the protruding stroma and the epithelial buds form the anlage of the caruncles (carefully observed).

The surrounding mesenchymal tissue areas appear more differentiated.

Epithelium buds in different stages of development, underlaid by stroma cells, as well as already expanded caruncles can be observed in the corpora and in cornua of fetuses with CRLs of $31.0 \mathrm{~cm}$ (fig. 1E, G, H) and $44.8 \mathrm{~cm}$. The epithelium of caruncles is a simple cuboid to columnar epithelium (fig. 1J). The nuclei are oval and are usually located basal or concentric in the cytoplasm. In contrast, the epithelium of the intercaruncular regions (fig. 1I) is (pseudo)stratified. Additionally, numerous new narrow epithelium buds are perceived in intercaruncular areas, which later transform to early caruncles. The stroma cells (in caruncular and intercaruncular regions) adjacent to the epithelium show no defined arrangement but are always more compactly arranged than the remaining loose endometrium and the developing caruncle stroma. Small round cells with little cytoplasm and dark round condensed nuclei are often located near the basement membrane or intermingled between the epithelium cells. Groups of these cells can be also seen in the caruncular stroma. The myometrium is now clearly recognizable (fig. 1K, L). The smooth muscle cells are in close contact to each other and arranged in a circular manner (fig. 1F). The tela subserosa is broader than in earlier stages, consisting of loosely arranged stroma cells. A marked longitudinal stratum musculare can be seen close to the tunica muscularis. Many prominent vessels can be recognized in the tela subserosa.

In uteri of fetuses with CRLs of 57.6 (fig. 1M), 58.7, 66.0 (fig. $1 \mathrm{~N}, \mathrm{O}$ ), and $72.5 \mathrm{~cm}$ (fig. $1 \mathrm{P}, \mathrm{Q}$ ) the caruncles increase in number and size. The endometrial stroma has expanded in width, showing an increase in vascularization (mainly in the caruncular stroma tissue). Epithelium buds are confined to the intercaruncular areas. The myometrium appears clearly reduced in width compared to earlier stages. Big vessels are localized in the myometrium border between the circular to longitudinal muscle layer. Furthermore, distinct vessels appear in the now very dominant tela subserosa. At a CRL of $72.5 \mathrm{~cm}$, big oval cells with round nuclei can be identified between the muscle cells. Numerous nerve fibers are observed in the tela subserosa.

Large and well-differentiated caruncles are seen in the fetal corpora uteri as well as in the cornua at a CRL of 90.0 and $94.0 \mathrm{~cm}$. Generally, the caruncles are covered by a simple columnar epithelium with narrow nuclei. In basal and apical areas, round cells with strongly stained nuclei are often intermingled with the columnar epithelium cells. The same cell type can also be seen increasingly in the area under the basement membrane as well as in caruncles stroma. The epithelium of the intercaruncular regions is also (pseudo)stratified, but the number of epithelial buds has strongly decreased. The number of small vessels in the stroma (fig. 1R) near the basement membrane is increased similarly to the bigger vessels in the remaining more loosely arranged caruncular stroma. The myometrium is well differentiated (fig. 1S) and with a varying orientation of the smooth muscle cells (circular and longitudinal). The stratum musculare longitudinal is well developed (fig. 1T). The tela subserosa is smaller but contains numerous big vessels, prominent nerve fibers as well as neurons.

\section{Expression Pattern of Laminin in Prenatal Bovine Uteri}

No differences in the expression of laminin can be observed between the corpora and the cornua in all investigated stages. In general, the epithelium and stroma are always negative for an antibody against laminin. In the developing myometrium, laminin-positive staining is observed. The basement membrane of the epithelium shows a distinct staining for laminin in all investigated prenatal uteri (both segments) in the caruncular as well as the intercaruncular area. Furthermore, the basement membrane of blood vessels is stained intensively laminin positive in all tissue layers during uterus development. In a later stage (CRL $94.0 \mathrm{~cm}$ ), single epithelium invaginations into the stroma (only into the intercaruncular regions) can be perceived with the help of the laminin-positive basement membrane. 

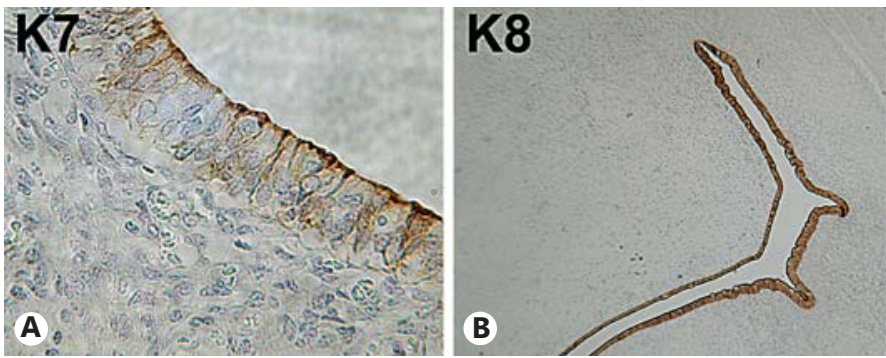

Fig. 2. Expression pattern of keratin 7 (K7), keratin 8 (K8), keratin 18 (K18), and keratin 19 (K19) proteins in the corpora and cornua uteri of different development stages. A The epithelium cells of the cornua uteri from a fetus with a CRL of $94.0 \mathrm{~cm}$ show a strong expression for $\mathrm{K} 7$ in the apical region. In some cells the whole cytoplasm is $\mathrm{K} 7$ positive. The nuclei are negative for the antibody against K7. B The caruncular and intercaruncular epi-

\section{Expression of Keratin 7 in Prenatal Bovine Uteri}

The endometrial stroma cells, the smooth muscle cells, as well as the subserosa/serosa cells are keratin 7 (K7) negative. In some cases dot-like K7-positive structures are observed in apical regions of epithelial cells, but also K7negative cells are detected (CRL 9.2-24.4 cm, corpora and cornua). Generally, from a CRL of $29.8 \mathrm{~cm}$ onwards, the apical $\mathrm{K} 7$ staining as well as the number of $\mathrm{K} 7$-positive cells increase (fig. 2A), and some cells show a K7 expression throughout the whole cytoplasm. In the cornua, the same K7 expression pattern as in the corpora is observed but with a reduced staining intensity. In fetuses with a $\mathrm{CRL}$ of $94 \mathrm{~cm}, \mathrm{~K} 7$ expression intensity is identical in the corpus and the cornua.

\section{Expression Pattern of Keratin 8 in Prenatal Bovine Uteri}

Generally, endometrial and perimetrial stroma cells, muscle cells, migrating cells as well as vessels are keratin 8 (K8) negative. The basal and apical regions of the epithelium (with no differences in the cornua and the corpora as well as intercaruncular and caruncular regions) show a positive reaction with an antibody against K8. In the cornua of fetuses with a CRL of $31.0 \mathrm{~cm}$ and the corpora of fetuses with $44.8 \mathrm{~cm}$ onwards, the whole cytoplasm expresses $\mathrm{K} 8$ (sometimes with a more intensive staining of the apical and basal region) (fig. 2B). The epithelial cell nuclei are K8 negative. From a CRL of 57.6 to $94.0 \mathrm{~cm}$ the cytoplasm of caruncular epithelial cells is regularly K8 positive, whereas in the intercaruncular epithelium cells the cytoplasm staining is weaker.

Fetal Development of the Bovine Uterus
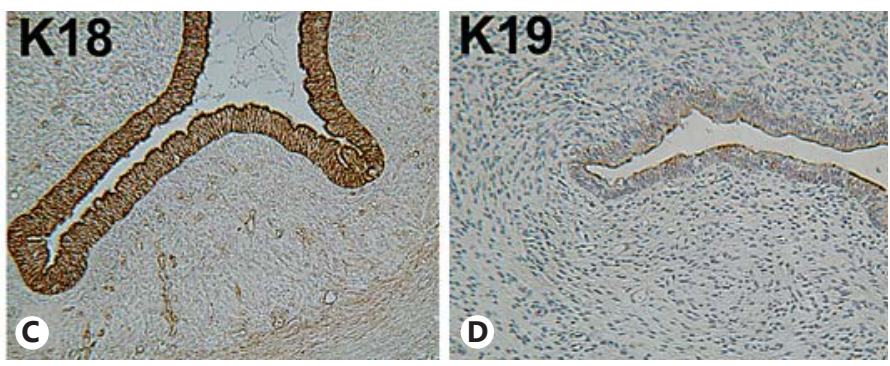

thelia show a distinct staining for K8. Cornua uteri of a fetus with a CRL of $44.8 \mathrm{~cm}$. C The cytoplasm of the cornua uteri epithelium from a fetus with a CRL of $31.0 \mathrm{~cm}$ shows a homogenous K18 expression. Note the positive vessels as well as the faint staining in the myometrium. D Single positive K19 reactions in the apical regions of the corpus uteri epithelium cells from a fetus with a CRL of $90.0 \mathrm{~cm}$.

\section{Expression Pattern of Cytokeratin 18 in Prenatal Bovine Uteri}

No differences in the cytokeratin 18 (K18) expression pattern can be observed between the corpora and the cornua uteri during all investigated stages. In early stages (from CRLs $9.2-15.8 \mathrm{~cm}$ ) K18 staining is more pronounced in the basal and apical cytoplasm, whereas from a CRL of $24.4 \mathrm{~cm}$ onwards the cytoplasm of epithelial cells is homogenously stained with an antibody against K18 (fig. 2C). Additionally, the K18 expression in the cytoplasm from a CRL of $24.4 \mathrm{~cm}$ onwards increases. Single K18-positive cells can be observed in the undifferentiated mesenchyme of fetuses with a CRL of $9.2-11.4 . \mathrm{cm}$. A very faint K18 expression is observed from a CRL of $24.4 \mathrm{~cm}$ onwards in the differentiated muscle cell layer. In contrast, no K18 reaction is observed within the stroma of caruncular or intercaruncular regions from a CRL of 24.4 $\mathrm{cm}$ onwards. The endothelium of vessels expresses K18 in the uterus of all prenatal stages. No K18 reaction can be detected in the migrating cells.

\section{Expression Pattern of Cytokeratin 19 in Prenatal Bovine Uteri}

The epithelium of corpora and cornua uteri of fetuses with a CRL of 9.2 and $11.4 \mathrm{~cm}$ is completely negative for cytokeratin 19 (K19). From $15.8 \mathrm{~cm}$ onwards, the apical epithelial regions are distinctly positive; a weaker reaction is detected in the middle to basal cytoplasm region. A similar immunohistochemical staining pattern is then found in the uteri of fetuses with a CRL of 31.0-66.0 cm. From a CRL of $72.0 \mathrm{~cm}$ onwards the K19 expression is again confined to the apical regions (fig. 2D) of the epi- 
thelium with occasionally distinct circumscribed positive reactions in the cytoplasm. A K19-positive immunostaining is recognizable in the serosa cells of the uterus from a CRL of $31.0 \mathrm{~cm}$ onwards. All other cell populations are K19 negative.

\section{Expression Pattern of Vimentin in Prenatal Bovine Uteri}

With some exceptions, vimentin shows a similar expression pattern in all parts during the examined stages. Briefly, the epithelium cells and the immigrated free cells in the epithelium are negative for vimentin. Vimentin staining in the undifferentiated mesenchymal cells (as long as the tissue layers could not be precisely discerned) is stronger than in the later developmental stages (fig. 3A, $\mathrm{B})$. The stroma directly beneath the epithelium (in caruncular and intercaruncular regions) is always stronger vimentin-positive than the remaining endometrial stroma (fig. 3C, D). In stages from a CRL of $9.4-66.0 \mathrm{~cm}$ the differentiating smooth muscle cells show a distinct (CRL $9.4-44.8 \mathrm{~cm}$ ) (fig. 2C) to weak (CRL $44.8-72.5 \mathrm{~cm}$ ) vimentin reaction, whereas in later stages (from a CRL of $72.5 \mathrm{~cm}$ onwards) the smooth muscle cells are vimentin negative. Additionally, single vimentin-positive polygonal cells can be observed between the smooth muscle cells during later stages (CRL 44.8-94.0 cm) of development. The smaller vessels express vimentin only weakly. In con- trast, the bigger vessels show a distinct immunostaining for vimentin in their tunica media. Vimentin-negative and -positive cells can be detected in the subserosa cells. In later stages some nuclei of the subserosa cells are also positive for vimentin.

\section{Expression Pattern of Collagen I in Prenatal Bovine Uteri}

Generally, no expression for collagen I can be observed in the epithelium cells, the tunica muscularis, the vessels endothelium as well as the nerve cells. In the (pseudo)stratified epithelium of the intercaruncular areas in fetuses with CRLs of 90.0 and $94.0 \mathrm{~cm}$, a punctual collagen I-positive reaction can be depicted in the more apical cytoplasmic areas (fig. 3G). No collagen I reaction can be recognized in the undifferentiated mesenchymal layers of earlier stages (fig. 3E). The stroma in the developing caruncles shows a collagen I staining in fetuses with a CRL of $31.0 \mathrm{~cm}$ and larger. In the more prominent caruncles of fetuses with a CRL of $44.8 \mathrm{~cm}$ onwards the positive reaction for collagen $\mathrm{I}$ is stronger in the basal areas of the caruncles compared to the regions adjacent to the epithelium (fig. 3F). In differentiating tela subserosa cells a weak collagen I expression is observed during the earliest stages of fetal development. The collagen I expression increases in subserosa cells from a CRL 29.8 $\mathrm{cm}$ onwards, both in the corpora and in the cornua.
Fig. 3. Expression patterns of vimentin (Vim), collagen I, S100, and SMA proteins in the corpora and cornua uteri of different development stages. A Undifferentiated mesenchymal cells surround the epithelium of the cornua uteri from a fetus with a CRL of $15.8 \mathrm{~cm}$ and show a distinct expression for the antibody against vimentin. The epithelium is vimentin negative. B The stroma tissue of the endometrium as well as of the differentiating myometrium is positive for the antibody against vimentin. The subserosa is mostly negative. Cornua uteri of a fetus with a CRL of $29.8 \mathrm{~cm}$. C, D In the caruncles of corpora (C) and cornua (D) uteri the caruncular stroma is distinctly positive in caruncular and intercaruncular regions. Note the more densely arranged stroma cells directly under the basal lamina of the epithelium. In the myometrium vimentin-positive as well as -negative cells can be observed. Fetus with a CRL of $29.8 \mathrm{~cm}(\mathbf{C})$ and $44.8 \mathrm{~cm}$ (D), respectively. E In earlier stages the undifferentiated mesenchymal layer show no collagen I (Col I) expression. In contrast, in the developing perimetrium a collagen I expression can be detected. Cornua of a fetus with a CRL of 29.8 $\mathrm{cm}$. $\mathbf{F}$ The positive reaction for collagen $\mathrm{I}$ is stronger in the basal stroma areas of the caruncles and in regions adjacent to the epithelium than in the remaining endometrial stroma tissue. Corpus of a fetuses with a CRL of $44.8 \mathrm{~cm}$. G Punctual collagen I reaction in the more apical cytoplasm of the epithelium of the cornua uteri from a fetus with a CRL of $94.0 \mathrm{~cm}$. H S100-positive vessels and nerve cells/fiber bundles in the developing corpus uteri subserosa of a fetus with a CRL of $24.4 \mathrm{~cm}$. I S100-positive cytoplasm and nuclei in the epithelium cells of intercaruncular regions (and of epithelium buds) from the corpus uteri of a fetus with a CRL of $58.7 \mathrm{~cm}$. J Strong S100-positive vessels in the caruncles stroma tissue (cornu uteri) of a fetus with a CRL of $66.0 \mathrm{~cm}$. K, L S100-positive epithelium cytoplasm and nuclei in the intercaruncular regions of the cornua uteri from a fetus with a CRL of $94.0 \mathrm{~cm}$. Note the tubular like invaginations into the underlying stroma tissue. $\mathbf{M}$ The smooth muscle layer is strongly SMA positive in the cornua uteri of a fetus with a CRL of $24.4 \mathrm{~cm}$. N, O SMA-positive longitudinal cells/fibers, protruding into the caruncles stroma in the corpus uteri of a fetus with a CRL of $29.8 \mathrm{~cm}(\mathbf{N})$ and the corpus uteri of a fetus with a CRL of $29.8 \mathrm{~cm}(\mathbf{O})$. P Big, polygonal SMA-negative cells between the myometrium smooth muscle cells in the cornua uteri of a fetus with a CRL of $31.0 \mathrm{~cm}$. Q Myometrium protruding into the caruncles stroma in the corpus uteri of a fetus with a CRL of $44.8 \mathrm{~cm}$. Antibody against SMA. R, S SMA-positive cells/ fibers, perpendicular to the myometrium in the cornua uteri of a fetus with a CRL of $66.0 \mathrm{~cm}$. Note the SMA-positive vessels. T Enlarged SMA-positive myometrium. Note the SMA-positive stratum muscularis longitudinal in the corpus uteri of a fetus with a CRL of $66.0 \mathrm{~cm}$. 
Generally, the collagen I protein staining is more prominent in collagen fibers of the tela subserosa, which are flanking the tunica muscularis (in stages from a CRL of $29.8 \mathrm{~cm}$ onwards). The serosa cells of the stages from CRLs $24.4-31.0 \mathrm{~cm}$ reacts with the collagen I antibody, whereas no reaction is seen in the remaining developing stages.
Expression Pattern of S100 in Prenatal Bovine Uteri

Usually, the endothelium of all blood vessels shows a strong reaction with a S100 antibody (fig. $3 \mathrm{H}, \mathrm{J}$ ). There are distinctly positive vessels in the stroma of the caruncles [which run parallel to the longitudinally arranged smooth-muscle marker (SMA)-positive smooth muscle cells]. Also nerve cells as well as nerve fibers show a posi-
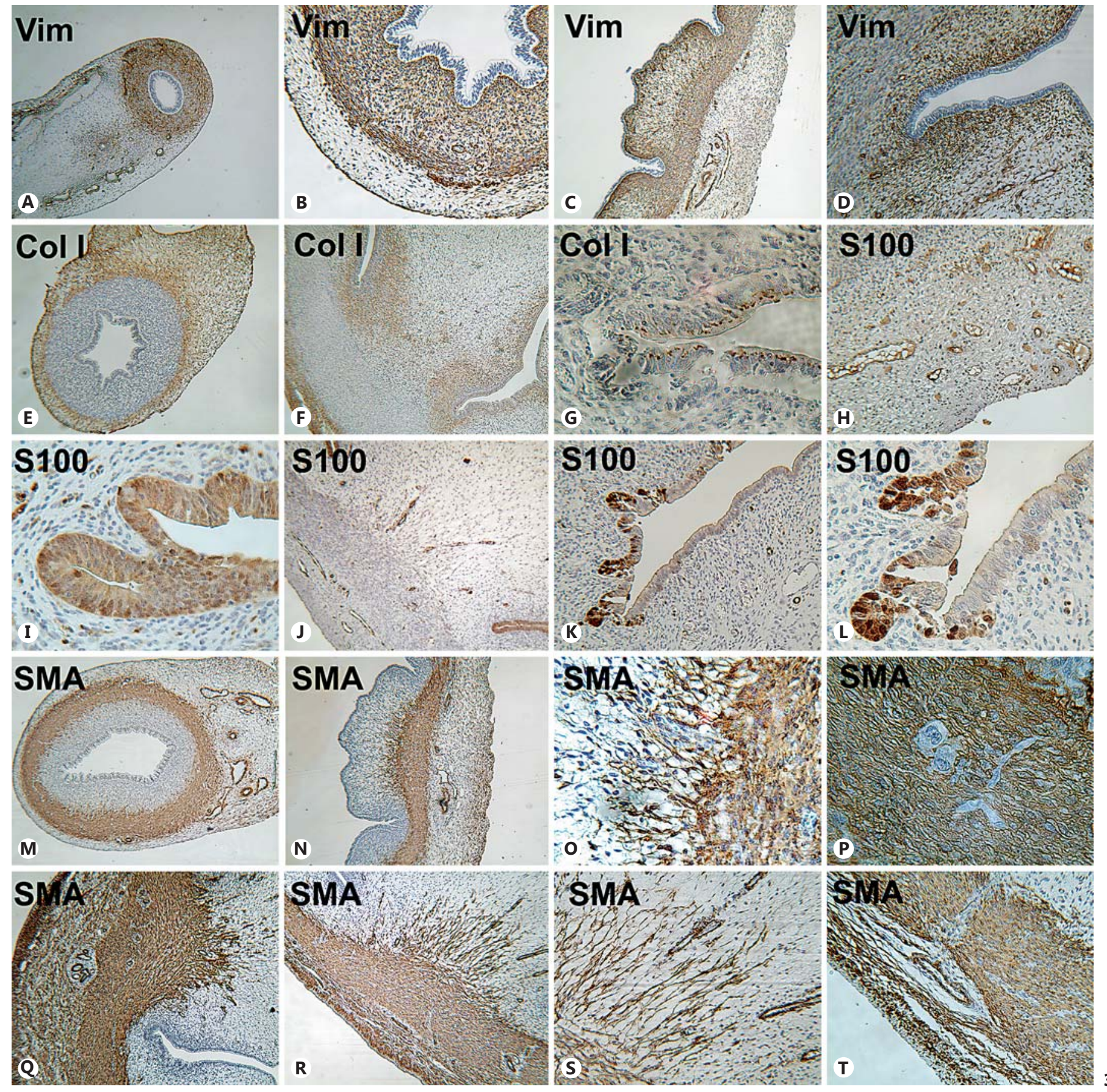

Fetal Development of the Bovine Uterus 
tive immunostaining for S100. In the tunica muscularis, single S100-positive nerve cells are seen between S100negative muscle cells in developing stages from a CRL of $44.8 \mathrm{~cm}$ onwards. The epithelial cells (until a CRL of 15.8 $\mathrm{cm}$ ) are $\mathrm{S} 100$ positive in parts of the uterus. During later stages, the S100 expression increases. Also some nuclei are immunostained. The expression is first more pronounced in several epithelium regions of the caruncles, but in later stages (CRLs 90-94 cm) an increase of expression in the intercaruncular epithelium is also seen in some areas (fig. 3I, K, L).

\section{Expression Pattern of SMA in Prenatal Bovine Uteri}

The epithelium and the endometrial stroma cells show no reaction with the antibody against SMA. A weak reaction for SMA can be detected in the developing tunica muscularis of corpora and cornua uteri from a CRL of $11.4 \mathrm{~cm}$ onwards. SMA-positive cells increase in number and intensity during myometrium differentiation (concomitantly, the number of vimentin-positive cells decreases) (fig. 3M, N). Later in development, the nuclei and the cytoplasm of most smooth muscle cells become SMA positive, but also some polygonal SMA-negative cells can be found (fig. 3P). From a CRL of $29.8 \mathrm{~cm}$ onwards, intensively SMA-immunostained smooth muscle cells occur, which are perpendicularly arranged to circular SMApositive muscle cell layers (fig. $3 \mathrm{~N}, \mathrm{O}, \mathrm{R}, \mathrm{S}$ ). These SMApositive cells are only recognizable in the stroma of caruncles. The strands of cells/fibers are accompanied by vessels with a SMA-positive tunica media running in the same direction. In the caruncles the SMA-positive smooth cells protrude into the endometrium (fig. 3Q). Additionally, the stratum muscularis longitudinale of the myometrium shows a strong staining with an antibody against SMA (fig. 3T). Some SMA-negative, large, polygonal cells can be found in the tunica muscularis (similar in their morphology to the vimentin-positive cells described above) from a CRL of $72.5 \mathrm{~cm}$ onwards.

\section{Discussion}

The bovine uterus is a uterus bicornis and consists anatomically of 2 cornua uteri, corpus uteri, and cervix uteri [König and Liebich, 2014]. The anatomy of the organ results from the fusion of the caudal parts of the Müllerian ducts [Rüsse and Sinowatz, 1998; König and Liebich, 2014]. Similarities as well as differences can be observed in the expression pattern of intermediate filaments (keratins and vimentin) and laminin in the Müllerian duct in comparison with the prenatal uterus. The basement membrane beneath the uterus epithelium is strongly positive for laminin in all investigated stages. This is not surprising as also the basement membrane of the Müllerian duct is strongly positive for laminin [Paranko et al., 1985; Kenngott and Sinowatz, 2008]. We already described the distribution pattern of different intermediate filaments during bovine Müllerian ducts development [Kenngott and Sinowatz, 2008]. The expression pattern of the intermediate filament in the early fetal uterus is somewhat different from that of the bovine Müllerian duct. No vimentin expression was found in the uterus epithelium in all investigated stages, whereas the epithelium of the bovine Müllerian duct is immune-positive for vimentin, especially in its caudal parts [Kenngott and Sinowatz, 2008]. The epithelium of the Müllerian duct was mostly negative for K8, K18, and K19 [Kenngott and Sinowatz, 2008]. However, the epithelial cells of the differentiating fetal bovine uterus showed a varying expression of the investigated keratins $(7,8,18$, and 19). In line with Kenngott and Sinowatz [2008] and Viebahn et al. [1987], we assume that intermediate filaments can change their expression patterns during the developing process. Therefore, their use as markers for the origin of cells appears limited, but they can be applied to identify characteristic differentiation stages [Franke, 1982; reviewed in Viebahn et al., 1987].

König and Liebich [2014] described 80-120 caruncles in the endometrium of ruminants. Caruncles and cotyledons join to placentoms, characteristic during ruminants' placentation [König and Liebich, 2014]. No fully developed caruncles can be observed during early fetal stages (corpora and cornua) of fetuses with a CRL of $9.2-15.8 \mathrm{~cm}$. The epithelium is simple cuboidal to (pseudo)stratified with bud-like epithelial protrusions, not stocked with mesenchymal stroma at this point. Wiley et al. [1987] found a simple columnar epithelium with no signs of caruncles or glandular formation in the uteri of fetal sheep of day 55-60. The bovine caruncle formation begins at a CRL of $15.8 \mathrm{~cm}$, both in the corpus and the cornua of the fetal uterus. Wiley et al. [1987] described nodular and internodular regions at day 100 in sheep. Like the fetal bovine early caruncles ('bud-like protrusions'), these nodules are formed by epithelial cells and the underlying mesenchyme. Yaumauchi [1964] identified early caruncles in the bovine uterus of a fetus with a CRL of 32-33 cm. Atkinson et al. [1984] described nodules with apical tips converting to caruncles in the developing bovine uterus. Additionally, they supposed the nodular sides forming the later glandular-intercaruncular areas in concert with the internodular regions. 
We conclude from the results of our investigation that the development of caruncles in the bovine uterus occurs in the following way: The epithelium initially builds epithelium buds protruding into the lumen. They increase in size and become supported by mesenchymal cells, and these structures are the first signs of caruncula. The fetal caruncles consist of a simple cuboidal to columnar keratin-positive epithelium and a vimentin-/collagen I-positive mesenchymal component. In the intercaruncular regions of the earlier developmental stages the epithelium is (pseudo)stratified, and new epithelial buds are formed, generating the basis for the development of additional caruncles. Similar, Yaumauchi [1964] described a bulge of mucosa tissue prior to the occurrence of caruncles in the uteri epithelium of fetuses from a CRL of $18-28 \mathrm{~cm}$. A similar bud-like formation process is also depicted in the developing mouse lung epithelium by Nogawa et al. [1998]. They observed a proliferation rate in budding areas being more increased than in the regions between single clefts. With ongoing aging of the bovine fetus, the epithelium buds of the intercaruncular regions decrease in number.

Wiley et al. [1987] presumed lymphocytes in the epithelium of the ovine fetal uterus of different development stages. Additionally, Yaumauchi [1964] observed leukocytes in the uterus wall of fetuses with a CRL of $33 \mathrm{~cm}$ onwards. In the bovine, we also found round cells with a dense round nucleus in the epithelium and in the endometrial stroma of developing caruncles from a CRL of $15.8 \mathrm{~cm}$ onwards. Further studies using antibodies against characteristic CD antigens are necessary to fully characterize the different lymphocyte subtypes.

An interesting observation is the occurrence of tubular epithelial invaginations in the intercaruncular regions and basal areas of caruncles in fetuses with a CRL of 94.0 $\mathrm{cm}$. We assume that this structure could be the anlagen of uterine glands. The invaginations exhibit a strong laminin-positive basement membrane. Atkinson et al. [1984] found the first glandular structures at day 250 in the internodular regions. In cattle, the authors described that epithelium cells of developing glands possess cytoplasmic processes in their basal part, which are in close contact with the denser packed stroma tissue. Atkinson et al. [1984] assumed that the interaction between connective tissue and glandular epithelium induce gland formation. In our study, immunostaining of collagen I gave a strong positive reaction in the intercaruncular areas and in the basal sides of evolving caruncles. Subsequently, the mesenchymal cells beneath the epithelium (in both segments as well as in the caruncular and intercaruncular regions) are stronger vimentin positive than the remaining endometrial stroma. In line with Atkinson et al. [1984], we found indication of uterine gland development during later times of gestation. Therefore, we support the hypothesis of previous studies [Anderson et al., 1975; Bareither and Verhage, 1980, both reviewed in Atkinson et al., 1984] that the beginning of the glandular development in the uterus is correlated with a high level of maternal estrogen during late gestation [Atkinson et al., 1984].

Wiley et al. [1987] reported that 2 mesenchymal zones could be distinguished from days $55-60$ by light microscopy. In the human fetal uterus, Konishi et al. [1984] described 2 undifferentiated mesenchymal layers in the 14th gestation week, the outer layer with elongated mesenchymal cells and the inner layer with more rounded cells. In prenatal bovine uteri, 2 different mesenchymal layers can be distinguished due to the morphology and orientation of the mesenchymal cells from a CRL of 15.8 $\mathrm{cm}$ onwards. In sheep, 3 layers have been discerned in the inner mesenchymal layer from day 90-100 [Wiley et al., 1987]; densely arranged stroma cells (with round nuclei) are located adjacent to the epithelium, an intermediate layer with loosely arranged cells containing elongated nuclei, and a third layer consisting of circularly orientated cells with eosinophilic cytoplasm and elongated nuclei. Wiley et al. [1987] further described an outer mesenchymal area with loosely arranged cells containing also elongated nuclei. In the bovine uterus similar areas are observed. Furthermore, the endometrial stroma can be subdivided in a dense layer of irregular stroma cells beneath the epithelium cells followed by a more loosely arranged stroma with mesenchymal cells possessing round nuclei. The circular orientated mesenchymal cells are distinctly SMA positive from a CRL of $24.4 \mathrm{~cm}$ onwards and therefore can be regarded as differentiated smooth muscle cells. The thickness as well as the SMA-staining intensity of the circular zone increase from a CRL of $24.4 \mathrm{~cm}$ onwards. In the human fetal uterus Konishi et al. [1984] supposed that smooth muscle cells originate from the undifferentiated mesenchymal cells. Therefore, Konishi et al. [1984] described the beginning of smooth muscle cell differentiation at week 18 of gestation. The myometrium could be exactly identified at the 31th gestation week in the fetal human uterus [Konishi et al., 1984]. Like Konishi et al. [1984] we also assume that the undifferentiated mesenchymal cells in the transitional zone between the endometrium and myometrium are the first to develop into differentiated SMA-positive smooth muscle cells. This is supported by a concurrent decrease in vimentin-staining 
intensity of this cell population. Longitudinal cells with increasing SMA-staining intensity are also seen in developing subserosa of the bovine uterus, possibly forming the stratum muscularis longitudinale [König and Liebich, 2014].

Interesting observations are the strong SMA-positive (perpendicular to the circular muscle layers) fiber-like structures in the more developed caruncula (from a CRL of $24.4 \mathrm{~cm}$ onwards). They are in close arrangement to SMA (endothelia, tunica media)-positive vessels. We assume that the structures can be an enhancement feature of the developing caruncula and found no similar description in the literature.

\section{Acknowledgement}

The authors thank Ms. Gabriele Russmeier for assistance with immunohistochemistry and Ms. Margarete Vermehren for help in language editing.

\section{Statement of Ethics}

The authors have no ethical conflicts to disclose.

\section{Disclosure Statement}

The authors have no conflicts of interest to declare.

\section{References}

Anderson WA, Kang YH, DeSombre ER: Estrogen and antagonist-induced changes in endometrial topography of immature and cycling rats. J Cell Biol 64:692-703 (1975)

Atkinson BA, King GJ, Amoroso EC: Development of the caruncular and intercaruncular regions in the bovine endometrium. Biol Reprod 30:763-774 (1984).

Bareither ML, Verhage HG: Effect of estrogen and progesterone on secretory granule formation and release in the endometrium of the ovariectomized cat. Biol Reprod 22:635-643 (1980).

Baumgartner EA: Zur Entwicklung des Genitaltraktes beim Rind. Universität Bern Dissertation (1910).

Boos A: Immunohistochemical assessment of collagen types I, III, IV and VI in biopsy samples of the bovine uterine wall collected during the oestrous cycle. Cells Tissues Organs 167:225238 (2000)

-Carpenter KD, Gray CA, Bryan TM, Welsh TH Jr, Spencer TE: Estrogen and antiestrogen effects on neonatal ovine uterine development. Biol Reprod 69:708-717 (2003).

Franke WW, Grund C, Kuhn C, Jackson BW, Illmensee K: Formation of cytoskeletal elements during mouse embryogenesis. III. Primary mesenchymal cells and first appearance of vimentin filaments. Differentiation 23: 43-59 (1982).

- Gray CA, Bartol FF, Tarleton BJ, Wiley AA, Johnson GA, et al: Developmental biology of uterine glands. Biol Reprod 65:1311-1323 (2001).

-Gray CA, Stewart MD, Johnson GA, Spencer TE Postpartum uterine involution in sheep: histoarchitecture and changes in endometrial gene expression. Reproduction 125:185-198 (2003).
Hayashi K, Carpenter KD, Welsh TH Jr, Burghardt RC, Spicer LJ, Spencer TE: The IGF system in the neonatal ovine uterus. Reproduction 129: 337-347 (2005).

Kenngott RA, Sinowatz F: Prenatal development of the bovine oviduct. Anat Histol Embryol 36:272-283 (2007).

Kenngott RA, Sinowatz F: Expression and distribution of intermediate-filament proteins and laminin during the development of the bovine Mullerian duct. Anat Histol Embryol 37:223230 (2008).

Kenngott RA, Vermehren M, Ebach K, Sinowatz F: The role of ovarian surface epithelium in folliculogenesis during fetal development of the bovine ovary: a histological and immunohistochemical study. Sex Dev 7:180-195 (2013).

King GJ, Atkinson BA, Robertson HA: Development of the bovine placentome during the second month of gestation. J Reprod Fertil 55: 173-180 (1979).

König HE, Liebich HG: Anatomie der Haussäugetiere, ed 6 (Schattauer, Stuttgart 2014).

Konishi I, Fujii S, Okamura H, Mori T: Development of smooth muscle in the human fetal uterus: an ultrastructural study. J Anat 139: 239-252 (1984).

Liebich HG: Funktionelle Histologie der Haussäugetiere und Vögel, ed 5 (Schattauer, Stuttgart 2009).

Mulisch M, Welsch U: Romeis-Mikroskopische Technik (Spektrum Akademischer Verlag, Heidelberg 2010).

Nogawa H, Morita K, Cardoso WV: Bud formation precedes the appearance of differential cell proliferation during branching morphogenesis of mouse lung epithelium in vitro. Dev Dyn 213:228-235 (1998).
Noll S, Schaub-Kuhnen S: Praxis der Immunhistochemie: Herausgegeben von Heinz Höfler und Klaus-Michael Müller (Urban\&Fischer, München 2000).

Paranko J, Virtanen I: Epithelial and mesenchymal cell differentiation in the fetal rat genialt ducts: changes in the expression of the cytokeratin and vimentin type of intermediate filaments and desmosomal plaque proteins. Dev Biol 117:135-145 (1986).

Paranko J, Foidart JM, Pelliniemi LJ: Basement membrane in differentiating mesonephric and paramesonephric ducts of male and female rat fetuses. Differentiation 29:39-49 (1985).

Rüsse I, Sinowatz F: Lehrbuch der Embryologie der Haustiere (Parey, Berlin 1998).

-Spencer TE, Dunlap KA, Filant J: Comparative developmental biology of the uterus: insights into mechanisms and developmental disruption. Mol Cell Endocrinol 354:34-53 (2012).

Taylor KM, Gray CA, Joyce MM, Stewart MD, Bazer FW, Spencer TE: Neonatal ovine uterine development involves alterations in expression of receptors for estrogen, progesterone, and prolactin. Biol Reprod 63:1192-1204 (2000).

Viebahn C, Lane EB, Ramaekers FC: The mesonephric (Wolffian) and paramesonephric (Mullerian) ducts of golden hamsters express different intermediate-filament proteins during development. Differentiation 34:175-188 (1987).

Wiley AA, Bartol FF, Barron DH: Histogenesis of the ovine uterus. J Anim Sci 64:1262-1269 (1987).

Yaumauchi S: Studies on morphogenesis of uterine horn, especially with uterine caruncule in Japanese native cattle. Jpn J Zootech Sci 35:92 (1964). 